\section{Mean Amplitudes of Vibration of Phosphine Borane and Trifluorophosphine Borane}

Enrique J. Baran

Centro de Química Inorgánica (CEQUINOR/CONICET, UNLP), Facultad de Ciencias Exactas, Universidad Nacional de La Plata, C. Correo 962, 1900-La Plata, Argentina

Reprint requests to Prof. Dr. E. J. B.; Fax: (54) 0221 4259485;

E-mail: baran@quimica.unlp.edu.ar

Z. Naturforsch. 60a, $554-556$ (2005); received April 20, 2005

The mean amplitudes of vibration of $\mathrm{PH}_{3} \mathrm{BH}_{3}$ and $\mathrm{PF}_{3} \mathrm{BH}_{3}$ were calculated from known spectroscopic and structural data between 0 and $1000 \mathrm{~K}$ and compared with those of related species. Bond peculiarities are also briefly discussed.

Key words: $\mathrm{PH}_{3} \mathrm{BH}_{3} ; \mathrm{PF}_{3} \mathrm{BH}_{3} ;$ Mean Amplitudes of Vibration; Bond Properties.

Phosphine borane, $\mathrm{PH}_{3} \mathrm{BH}_{3}$, and trifluorophosphine borane, $\mathrm{PF}_{3} \mathrm{BH}_{3}$, are both weak Lewis-type acid-base complexes. Their existence has been known for a relatively long time $[1,2]$ but their general properties encompass a continuous interest and research activity hitherto (cf. for example [3] and references therein).

In order to contribute to a deeper understanding of the vibrational properties of these systems, we have now performed the calculation of the mean amplitudes of vibration of the two mentioned complexes, using known vibrational-spectroscopic data.

The calculations were performed in two steps; firstly, the amplitude values of the $\mathrm{BH}_{3}$ and $\mathrm{PX}_{3}$ components of both compounds were obtained with the method of the characteristic vibrations of Müller et al. [4] (cf. also [5, 6]). Secondly, the values for the P-B bonds were estimated with the approximate method of Kimura and Kimura [7] (cf. also [8,9]), considering $\mathrm{X}_{3} \mathrm{P}_{-}-\mathrm{BH}_{3}$ as a diatomic species that presents only one degree of freedom (the stretching of the $\mathrm{P}-\mathrm{B}$ bond).

In the case of $\mathrm{PF}_{3} \mathrm{BH}_{3}$, the necessary vibrational frequencies and structural parameters were taken from the recent paper of Jensen [3]. For $\mathrm{PH}_{3} \mathrm{BH}_{3}$ the used vibrational data were those reported by Taylor et al. [10] whereas the molecular parameters were obtained from
Table 1. Calculated mean amplitudes of vibration (in $\AA$ ) of $\mathrm{PH}_{3} \mathrm{BH}_{3}$.

\begin{tabular}{cccccc}
\hline$T(\mathrm{~K})$ & $u_{\mathrm{B}-\mathrm{H}}$ & $u_{\mathrm{P}-\mathrm{H}}$ & $u_{\mathrm{B}-\mathrm{P}}$ & $u_{\mathrm{H} \ldots \mathrm{H}}\left(\mathrm{BH}_{3}\right)$ & $u_{\mathrm{H} . . \mathrm{H}}\left(\mathrm{PH}_{3}\right)$ \\
\hline 0 & 0.0878 & 0.0849 & 0.055 & 0.139 & 0.146 \\
100 & 0.0878 & 0.0849 & 0.055 & 0.139 & 0.146 \\
200 & 0.0878 & 0.0849 & 0.056 & 0.139 & 0.146 \\
298.16 & 0.0878 & 0.0849 & 0.058 & 0.140 & 0.147 \\
300 & 0.0878 & 0.0849 & 0.058 & 0.140 & 0.147 \\
400 & 0.0879 & 0.0849 & 0.062 & 0.141 & 0.148 \\
500 & 0.0879 & 0.0850 & 0.067 & 0.142 & 0.151 \\
600 & 0.0881 & 0.0852 & 0.071 & 0.145 & 0.154 \\
700 & 0.0885 & 0.0855 & 0.075 & 0.148 & 0.158 \\
800 & 0.0891 & 0.0860 & 0.080 & 0.151 & 0.162 \\
900 & 0.0898 & 0.0867 & 0.084 & 0.154 & 0.166 \\
1000 & 0.0907 & 0.0876 & 0.088 & 0.158 & 0.171 \\
\hline
\end{tabular}

Table 2. Calculated mean amplitudes of vibration (in $\AA$ ) of $\mathrm{PF}_{3} \mathrm{BH}_{3}$.

\begin{tabular}{cccccc}
\hline$T(\mathrm{~K})$ & $u_{\mathrm{B}-\mathrm{H}}$ & $u_{\mathrm{P}-\mathrm{F}}$ & $u_{\mathrm{B}-\mathrm{P}}$ & $u_{\mathrm{H} \ldots \mathrm{H}}$ & $u_{\mathrm{F} \ldots \mathrm{F}}$ \\
\hline 0 & 0.0868 & 0.0389 & 0.048 & 0.139 & 0.059 \\
100 & 0.0868 & 0.0389 & 0.048 & 0.139 & 0.059 \\
200 & 0.0868 & 0.0390 & 0.049 & 0.139 & 0.062 \\
298.16 & 0.0868 & 0.0394 & 0.051 & 0.139 & 0.067 \\
300 & 0.0868 & 0.0394 & 0.051 & 0.139 & 0.067 \\
400 & 0.0868 & 0.0403 & 0.054 & 0.140 & 0.073 \\
500 & 0.0869 & 0.0416 & 0.057 & 0.142 & 0.079 \\
600 & 0.0871 & 0.0432 & 0.061 & 0.145 & 0.085 \\
700 & 0.0874 & 0.0450 & 0.065 & 0.148 & 0.090 \\
800 & 0.0879 & 0.0469 & 0.068 & 0.151 & 0.096 \\
900 & 0.0887 & 0.0488 & 0.072 & 0.155 & 0.101 \\
1000 & 0.0895 & 0.0507 & 0.075 & 0.158 & 0.106 \\
\hline
\end{tabular}

the microwave study of Durig et al. [11]. A set of force constants for both species, derived from slightly different frequency data as those employed here, but with the same general assignment scheme, are also known [12] and may be useful for comparative purposes.

The results of the mean amplitude calculations, in the temperature range between 0 and $1000 \mathrm{~K}$, are shown in Tables 1 and 2 .

A comparison of these data immediately shows that in both species the $\mathrm{BH}_{3}$ fragment shows comparable mean amplitude values, although they are somewhat higher in the case of $\mathrm{PH}_{3} \mathrm{BH}_{3}$, pointing to a slight $\mathrm{B}-\mathrm{H}$ bond weakening in this case, in comparison to $\mathrm{PF}_{3} \mathrm{BH}_{3}$. This trend is in excellent agreement with the respective force constants, which are also only slightly lower in the case of $\mathrm{PH}_{3} \mathrm{BH}_{3}$ (3.121 mdyn/ $\mathrm{A}$ in $\mathrm{PH}_{3} \mathrm{BH}_{3}$ vs. $3.202 \mathrm{mdyn} / \AA$ in $\mathrm{PF}_{3} \mathrm{BH}_{3}$ [12]). Interestingly, the mean amplitude values for the non-bonded $\mathrm{H} \cdot \mathrm{H}$ pairs in both species are practically identical in the full temperature range. 
Although values for mean amplitudes of vibration of other species containing B-H bonds are relatively scarce $[5,13]$, it should be mentioned that the values found here are somewhat lower than those calculated in $\mathrm{BH}_{3} \mathrm{CO}$ [13] and in $\mathrm{BH}_{4}{ }^{-}$[14], but are comparable to those determined for the $\mathrm{B}-\mathrm{H}$ bond of $\mathrm{HBCl}_{2}$ [15].

Regarding the mean amplitude values of the $\mathrm{P}-\mathrm{H}$ bonds in $\mathrm{PH}_{3} \mathrm{BH}_{3}$ they are only somewhat lower than those of the B-H bonds, in the full temperature range, also in agreement with their force constant (3.295 mdyn/ $\AA$ [12]). The calculated value is also comparable to that of phosphine (0.0869 $\AA$ at $298 \mathrm{~K}$ [5]). The mean amplitude values of the non-bonded $\mathrm{H} \cdots \mathrm{H}$ pairs of this $\mathrm{PH}_{3}$ fragment are higher than those corresponding to the $\mathrm{BH}_{3}$ moiety.

The mean amplitudes of vibration of the $\mathrm{PF}_{3}$ fragment of $\mathrm{PF}_{3} \mathrm{BH}_{3}$ show that the $\mathrm{P}-\mathrm{F}$ bond is the strongest of all the linkages investigated in this study, a fact also confirmed by the particularly high value of the corresponding force constant (6.124 mdyn/ $\AA$ [12]). Besides, also the amplitude values for the non-bonded F...F pairs are appreciably lower than those corresponding to all the other calculated non-bonded pairs.

Values calculated for the mentioned $\mathrm{PF}_{3}$ fragment are highly characteristic for this bond, as they lie in the same range as in $\mathrm{PF}_{3}, \mathrm{PF}_{5}, \mathrm{~F}_{3} \mathrm{PO}, \mathrm{F}_{3} \mathrm{PS}$ [5] and $\mathrm{PF}_{2} \mathrm{X}$ $(\mathrm{X}=\mathrm{Cl}, \mathrm{Br}, \mathrm{I})[5,16]$.

Finally, a comparison of the characteristics of the P-B linkages in both species shows that this bond presents lower mean amplitude values in the case of $\mathrm{PF}_{3} \mathrm{BH}_{3}$, also in excellent agreement with the corresponding force constants $\left(2.295 \mathrm{mdyn} / \AA\right.$ for $\mathrm{PF}_{3} \mathrm{BH}_{3}$ and $1.958 \mathrm{mdyn} / \AA$ for $\mathrm{PH}_{3} \mathrm{BH}_{3}$ [12]), pointing to

[1] E. L. Gamble and P. Gilmont, J. Am. Chem. Soc. 62, 717 (1940).

[2] R. W. Parry and T.C. Bissot, J. Am. Chem. Soc. 78, 1524 (1956).

[3] J. O. Jensen, J. Mol. Struct. (Theochem.) 673, 165 (2004).

[4] A. Müller, C. J. Peacock, H. Schulze, and U. Heidborn, J. Mol. Struct. 3, 252 (1969).

[5] A. Müller, E. J. Baran, and K. H. Schmidt, Characteristic Mean Amplitudes of Vibration; in: Molecular Structures and Vibrations (Ed. S. J. Cyvin), Elsevier, Amsterdam 1972.

[6] E. J. Baran, An. Asoc. Quím. Argent. 61, 141 (1973).

[7] K. Kimura and M. Kimura, J. Chem. Phys. 25, 362 (1956). a slightly stronger $\mathrm{P}-\mathrm{B}$ interaction in the case of $\mathrm{PF}_{3} \mathrm{BH}_{3}$.

There has been considerable discussion regarding the nature of this P-B interaction in this type of acidbase complexes [11,17-19], as this kind of interaction is relatively difficult to rationalize because it depends on a delicate balance between different concurrent factors (for example, $\sigma$-bond ability, $\pi$-accepting ability and effects related to steric demands, cf. for example [20]). Interestingly, P-B bond orders estimated on the basis of the formerly calculated force constants showed values of 0.78 in $\mathrm{PH}_{3} \mathrm{BH}_{3}$ and of 0.92 in $\mathrm{PF}_{3} \mathrm{BH}_{3}$ [12], pointing to the presence of polar contributions to the bonding.

On the other hand, in the most recent theoretical study of $\mathrm{PF}_{3} \mathrm{BH}_{3}$ [3] the electron distribution and the nature of the occupied valence orbitals were analyzed using the total overlap population (Mulliken electron population). The results suggest that the bonding in this molecule may be described as relatively strong single $\sigma$-bonds between the P-B, P-F and B-H centers. Therefore, the slight differences observed in the P-B strengths in both phosphine boranes, and reflected in the mean amplitude values and in the corresponding force constants may, eventually, arise in the differences of the dipole moments of $\mathrm{PF}_{3}$ and $\mathrm{PH}_{3}(1.03 \mathrm{D}$ vs. $0.55 \mathrm{D}[20,21]$ ) (cf. also [17, 22]).

\section{Acknowledgements}

This work was supported by the Universidad Nacional de La Plata (Project X-339) and the "Consejo Nacional de Investigaciones Científicas y Técnicas de la República Argentina", the author being a member of the Research Career from this organization.

[8] E. J. Baran, Z. Physik. Chem. 255, 1022 (1974).

[9] E. J. Baran, Z. Naturforsch. 58a, 36 (2003).

[10] R. C. Taylor, R. W. Rudolph, R. J. Wyma, and V. D. Dunning, J. Raman Spectrosc. 2, 175 (1974).

[11] J. R. Durig, Y. S. Li, L. A. Carriera, and J. D. Odom, J. Am. Chem. Soc. 95, 2491 (1973).

[12] W. Sawodny and J. Goubeau, Z. Anorg. Allg. Chem. 356, 289 (1968).

[13] S. J. Cyvin, Molecular Vibrations and Mean Square Amplitudes, Elsevier, Amsterdam 1968.

[14] E. J. Baran, Z. Phys. Chem. (Leipzig) 257, 610 (1976).

[15] E. J. Baran, Monatsh. Chem. 124, 287 (1993).

[16] I. Elvebredd, B. Vizi, S. J. Cyvin, A. Müller, and B. Krebs, J. Mol. Struct. 2, 158 (1968). 
[17] A. H. Cowley and M. C. Damasco, J. Am. Chem. Soc. 93, 6815 (1971).

[18] R. W. Rudolph and C. W. Schultz, J. Am. Chem. Soc. 93, 6821 (1971).

[19] P. S. Bryan and R. L. Kuczkowski, Inorg. Chem. 11, 553 (1972).
[20] D. M. P. Mingos, Essential Trends in Inorganic Chemistry, Oxford University Press, Oxford 1998.

[21] H. B. Gray, Electrons and Chemical Bonding, W. A. Benjamin, New York 1965.

[22] R. W. Rudolph and R. W. Parry, J. Am. Chem. Soc. 89, 1621 (1967). 